\title{
Redressing the balance: Bruce Norval
}

Steve Chaplin

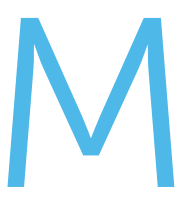

onday 24th September 2018 was the first day of the preliminary hearings of the UK Infected Blood Inquiry ${ }^{[1]}$. Two earlier

inquiries, dismissed as whitewashes, failed to provide answers and committed campaigners had now been rewarded. The Inquiry would examine the circumstances in which people under the care of the National Health Service (NHS) were given blood and blood products contaminated with HIV and hepatitis viruses, and possibly Creuzfeldt-Jakob disease (CJD); the impact on those infected and affected; the nature, adequacy and timeliness of the response from agencies involved; to what extent individuals may have been misled and denied treatment; and whether those agencies and individuals covered up the facts.

The first three days were held in public, given over to opening statements that included witness accounts from people with haemophilia and their families. Their stories are profoundly moving. The Inquiry is truly an historic step towards accountability for the government, the NHS, health professionals and all involved in haemophilia care in the UK decades since 1970. The man who worked for many years to make this a reality is Bruce Norval.

Bruce was born in Edinburgh in 1965. At age three he was admitted to hospital with bleeding from a fall; after three months on the ward, he was diagnosed with haemophilia B. It did not make much difference to him at the time.

"I tended to only bleed when I had an accident. I was a wild kid - I climbed walls, I climbed trees

STEVE CHAPLIN

Haemnet, UK. Email: steveahaemnet.com

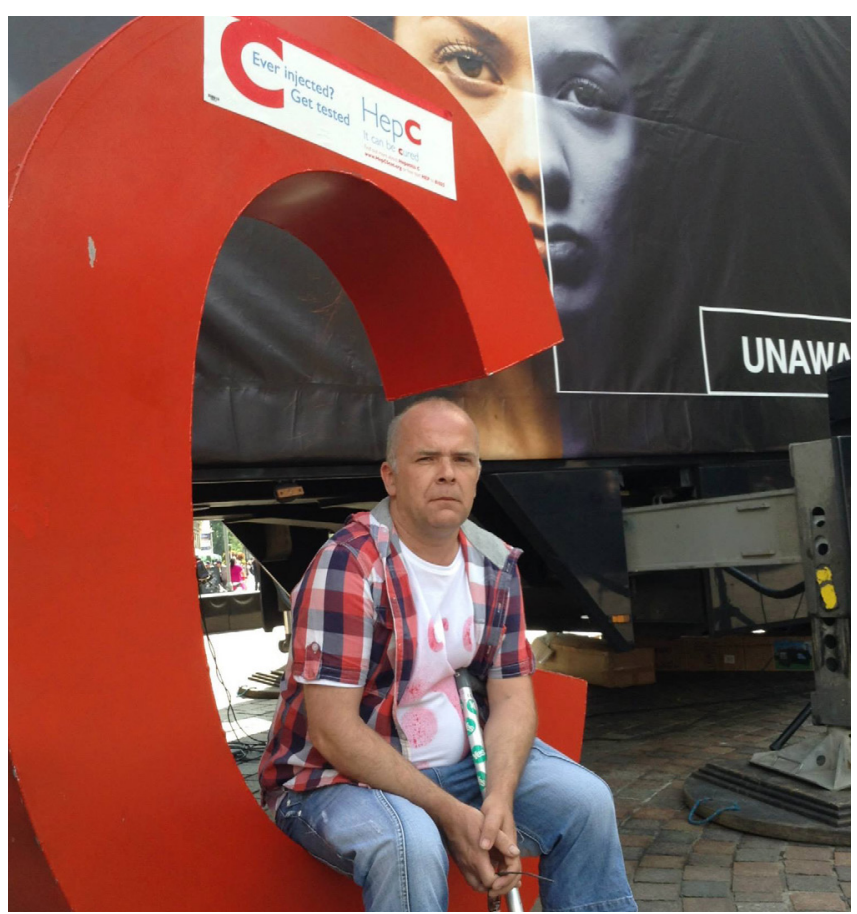

Bruce Norval is one of thousands of haemophiliacs in the UK - including many who died - who contracted hepatitis $C$ after receiving treatment with contaminated blood products in the 1970 s and 1980 s. He has been vocal in the campaign to secure justice for those affected by the Contaminated Blood Scandal for almost three decades.

- so when I did have a bleed it was a split head, blood pouring from my face. I always looked like somebody who had come from a battlefield, my dad said. Not so much the spontaneous joint bleed stuff; it was more about really open, very spectacular amounts of blood - falling off climbing frames, falling out of trees. When I got into my teens, occasional punch-ups."

He recollects a boisterous childhood but his father revealed, shortly before he died, that his parents had tried to protect him. They had tried to stop him taking

This is an Open Access article distributed under the terms of the Creative Commons Attribution-NonCommercial-NoDerivs License (https://creativecommons.org/licenses/by-nc-nd/3.0/) which permits use and distribution in any medium, provided the original work is properly cited, the use is non-commercial, and no modifications or adaptations are made. Copyright is retained by the authors. 
risks, but then realised it had been a mistake to restrain this energetic boy. Bruce recognises that there can be a gap between parental concern and the views of a child who has known no other life.

"I do think that we get very casual about what other people find is really disturbing. Whether it's bleeds or viruses, it's been our life, it's scary, so it tends to be something that we just say, 'Okay,' and shrug it off. 'My knee's bleeding - I'll just tie it up and go to the pub anyway.' But your parents are suffering - they care and they love you, they're seeing pain inflicted on their child."

Bruce's first treatment with Factor IX was in 1973. At the time it made him feel like Superman - not only did it stop the acute bleed, but the many minor cuts that come from being an active eight year-old also miraculously healed. And so it continued for several years until, in his early teens, his schoolwork began to suffer. Once top of the class, he began to struggle. He became aggressive, disruptive and isolated, and his relationship with his family broke down (and never recovered). He had night sweats so severe that, thinking he had wet the bed, he would sneak the sheets into the washing machine and remake the bed before his mother came home from work. These were early signs of liver damage: he had been infected with hepatitis $C$.

Bruce was not told of the diagnosis, though with hindsight he realises his liver function was being monitored routinely. He was not told of the diagnosis even when he began a career in nursing. By his early twenties he was too sick to work. On top of the challenges of living with haemophilia and hepatitis, post-traumatic stress disorder makes him sweat and shake. Bruce wants health professionals to understand the anger that he and others with haemophilia feel only then a conversation can begin about building a better future, starting with better care for children.

"I would love to see a point where it is an automatic thing that when a child is diagnosed with haemophilia, not only do you bring in the haemophilia team, you bring in the child development team and that child has an ongoing relationship with that team throughout their growing up, right into their late teens..."

That service should be extended to siblings, whose experiences are not fully recognised, and to support the family as a whole as they cope with a disabled child (or maybe two or three). One of the skillsets most needed but most often missing from treatment centres is that of the social worker.

Such initiatives should take into account the fact that children have their own ways of dealing with problems. Bruce recalls how he reacted to bleeds as a child:

"You grow up quickly when you've got these kinds of conditions, in certain ways. Yes, you stay a child as well. But in certain ways you grow up quickly. I can remember walking two miles with a fractured skull because I knew that if I stopped any earlier I would have to explain haemophilia to the police. It was far safer for me to get somewhere where somebody knew, so that I didn't have to start from scratch. I was eight years old, split my head, didn't want to leave my bike behind because it was going to get stolen, so I walked my bike home. The blood was pouring down my head, so I made a little peak just above my eye and the blood dripped down there, so I could still see. And I held my bike with my other hand and pushed it a mile and a half back home."

Children respond best to the parent who is measured and controlled, he continues, but parents need support to carry out that role.

\section{"I remember sitting on a doorstep as a young boy, with a split head, not wanting to go in because the only parent in the house was my father, who panicked. So, I sat for nearly an hour, hiding round the corner of the house, waiting for my mum to come home because my mum was the one that didn't panic, she did the first aid."}

This resilience is an untapped resource in haemophilia care:

\begin{abstract}
"Families need to understand haemophilia children are quite tough. You experience pain very early on in life and it becomes a norm. People look at us and they make the mistake of thinking... it's putting themselves in that situation, 'If that was me.' The thing is, we don't know any different; we've always been like this."
\end{abstract}

When Bruce found himself sharing a hospital ward with other boys with haemophilia, they would compare bleeds and number of stitches to see whose was worst. Kids today are no different, he says. They have to deal 


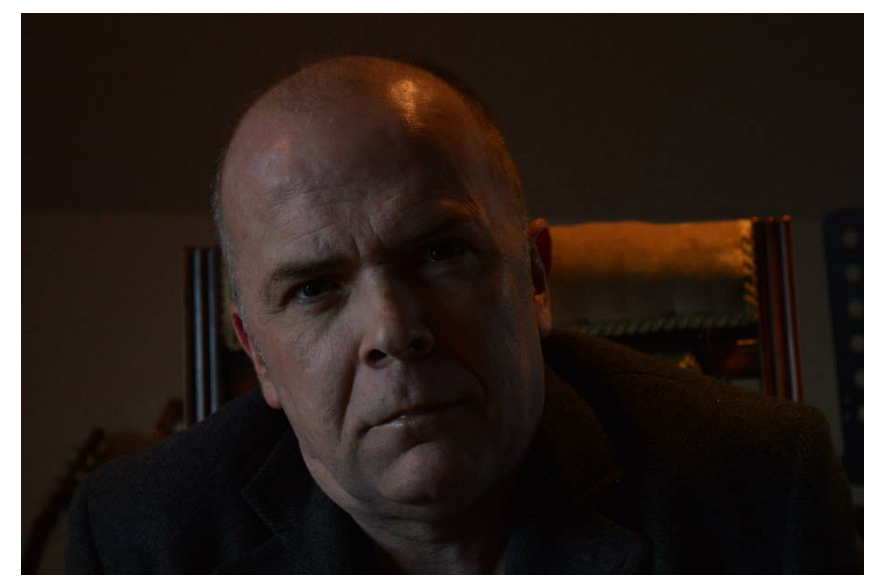

Image: Bruce is an advocate for improved care and support for children with haemophilia and their families. Once a nurse himself, he sees the role of nurses as being particularly important.

with reactions to ports, needle phobia, overcoming hurdles like school attendance. They can recognise better than anyone when they have a bleed; they're already experts on living with haemophilia and they've earned the right to be collaborative partners in their care.

For that to succeed, there has to be honesty from the outset - even about issues that seem trivial to adults:

"Don't say, 'Small scratch' - please, never say, 'Small scratch.' When you've got tiny wee arms, it's a big jaggy needle. You say something along the lines of, 'Sorry, this is going to hurt. Look at your mum.' Be honest with the kid. And doctors do it all the time: 'Small scratch.' I'm sorry - it's the size of a small stick and that to him is a very big needle."

Empowerment goes hand in hand with self-advocacy but what seems to be lacking in haemophilia care is an effective group through which individuals and families can learn from one another. Social media offers an accessible way to share experiences and find support, but treatment centres could usefully develop a national self-advocacy model that ensures access for everyone. Such groups are far better run by parents, calling on specialist advice only when they need to tackle specific issues. The support that comes from common experience is invaluable, Bruce says.

"One of the most embarrassing things that happens as a little boy - and I'm just saying this because I think it has to be said - when you masturbate as a haemophiliac you will bleed into your penis. No boy is going to go to his mum and say, 'Mum, I've got a bleed into my willy, because he knows he's been masturbating. I remember speaking... I had some bleeds in my willy and pretended I didn't have a bleed. So, there has to be a point where that child can at least turn around to one of his pals and say, 'Does that happen to you as well? Oh, right. That's okay, then.' And that's the important point: 'It's not weird'... Being the sixteen-year-old boy, being able to turn around to a seventeen-year-old boy and saying, 'Did you tell your girlfriend you had haemophilia before you asked her out? Or did you wait until you'd gone out for a couple of dates?' That kind of mentoring, that kind of support, that commonality, common contact is totally undervalued, I think, in medicine."

His experience has left Bruce with a critical view of health services, not only of the actions of various professions but also of the medicalisation of care.

"I speak to a number of parents of younger children, I see bits and pieces that I really like, I see bits and pieces that I'm uncomfortable with. I have issues with ports: I think there are far too many infections... I think they damage confidence in the hospitals sometimes because of the problems related to them. Some of the mothers have said to me that they didn't feel properly involved in understanding the risk to the child, having the port."

This criticism is rooted in the primacy of the child and here he sees the role of nurses as especially important. Haemophilia centres need nurses who can call on years of experience because they are the people who patients and families learn to trust. It follows that centres need to value and retain these experienced people. Bruce says he tried to be the kind of nurse who would recognise when someone needed comforting and would, no matter how busy he was, put an arm round their shoulder. It is almost old-fashioned nursing, he says, providing care in a fundamental way.

Not everyone is the same, of course. Some people want more intensive support, others independence.

"... with the new treatments coming up, yes, I think it's very important that the disease is not the focus of your life, and attending hospital and sticking needles in yourself is not the focus of 
your life - that's just a secondary thing. It should become just something that you do and you get on with your life."

The clearest distinction is between people with severe haemophilia, who are heavily reliant on the multidisciplinary team, and those with a moderate or mild disorder who seek help only when they think they need it. They demand little of the service, but health professionals recognise that individuals with a less severe bleeding disorder often fall between the gaps in care.

"... there's a group of us who the nurses forget about; who get to fifteen/sixteen years old and never come back until we're in our twenties, and then we've already got damaged joints, we've already got harm that could have been avoided."

This is where the value of skilled nursing early in life is evident.

"It's the nurses who have to develop oldfashioned holistic modelling to empower each child who's going to be different, whose parent dynamic and family dynamic is going to be different; the way needs are expressed and the way needs are asked for is going to be different. To me, that adaptability is what nursing is about."

A successful nurse-patient relationship is one that survives well into adulthood. Bruce recently met the nurse, now an elderly lady, who looked after him as a child - he gave her a big hug.

"...when I was in extreme pain, she sat by my bed, she gave me a cuddle, gave me a hug. As a wee kid, she held me in her arms. My first day out, this nurse took me out, just to the park so I could get some fresh air after spending weeks on the ward. So, you have this love for these people. The nurses have to understand that. It's quite an emotional experience having so much pain and going into a unit and coming away with that pain beginning to be resolved. And these people, these individuals who, as a young child, almost had magical powers to take your nasty pain away. That relationship kind of stays, even into adult life. I've spoken to haemophiliacs who are in their fifties and sixties who still view members of staff very fondly, despite what we now know about what wasn't being said and what should have been said. It's very hard to detach yourself from that."

That qualification about what was not being said returns matters to the present day. Bruce is frank about the relationship between patients and health professionals following the infected blood scandal. For those affected, the damage is severe and irrevocable.

"For those of us that are infected, there is no more trust. I'm sorry. I won't apologise. To every doctor, you're not getting it back. We will treat you with scepticism and you'll have to deal with it... Make me a partner in what you're doing. I'm never going to trust."

And that is the way forward. Nurses should think about how to build more collaborative relationships with their patients - it is "not so much a repair job as a revolution job," Bruce says. This will need respect from health professionals for what people have been through:

"When the Inquiry raises something and that parent says to you, don't dismiss it. If you can't answer it, say, 'I can't answer it, but I'll ask someone..."'

And it also means redressing the balance of power between patient and clinician:

"I think one of the things health professionals need to embrace is they see themselves as the pioneers - they're not, their patient is. Your patient is the one that's going over the edge; you're just sticking the needle in. Your patient is the pioneer: he's the one taking the risk. I think we've come to the point where we need to have a much better relationship with each other."

The Infected Blood Inquiry is likely to be traumatic for everyone in the haemophilia community and there will be many wounds to heal. Hopefully, justice will be done. The good that will come from this will be a stronger voice for people with bleeding disorders and their families, and a more open and collaborative relationship with health professionals. For that we will thank Bruce and the many who, like him, have suffered and are suffering still.

\section{ACKNOWLEDGEMENTS}

The authors have advised no interests that might be perceived as posing a conflict or bias. 
Informed consent has been obtained from the individual reported in this article.

\section{REFERENCES}

1. Infected Blood Inquiry. 2018. Available at:

www.infectedbloodinquiry.org.uk (accessed 18 October 2018).
HOW TO CITE THIS ARTICLE:

Chaplin S. Redressing the balance: Bruce Norval. J Haem Pract 2019; 6(1:suppl): S10-S14. https://doi.org/10.17225/

\section{0}

haemnet

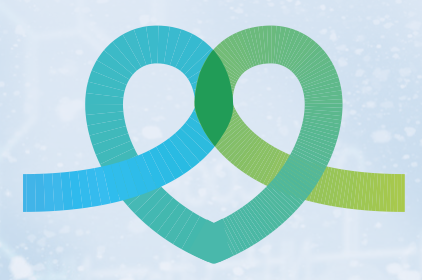

\section{The Journal of} Haemophilia Practice

\section{An open-access journal for sharing experience in the care of people with bleeding disorders}

